\title{
A rare case of Ganglioneuroblastoma Encapsulated in Pheochromocytoma
}

\section{Nathália Vieira Sousa ${ }^{1, *}$, Luísa Coelho Marques de Oliveira ${ }^{1}$, Paulo José Oliveira Cortez, Vitor Engrácia Valenti², David Mathew Garner ${ }^{3}$, Roseane de Souza Candido Irulegui ${ }^{1}$, Dalmo Antônio Ribeiro Moreira ${ }^{1,4}$}

\author{
${ }^{1}$ Faculdade de Medicina de Itajubá, Av. Renó Júnior, 368 - São Vicente, Itajubá, MG, Brazil \\ ${ }^{2}$ Programa de Pós-Graduação em Fisioterapia, Faculdade de Ciências e Tecnologia, UNESP, Rua Roberto Simonsen, 305 , \\ Presidente Prudente, SP, Brazil \\ ${ }^{3}$ Department of Biological and Medical Sciences, Faculty of Health and Life Sciences, Oxford Brookes University, Gipsy \\ Lane, Oxford OX3 0BP, United Kingdom \\ ${ }^{4}$ Instituto Dante Pazzanese de Cardiologia, Av. Dr. Dante Pazzanese, 500, São Paulo, SP, Brazil \\ * Corresponding author: Faculdade de Medicina de Itajubá, Av. Renó Júnior, 368 - São Vicente, Itajubá, MG, Brazil; e-mail: \\ nathaliavieira100@hotmail.com
}

Summary: Pheochromocytoma and Ganglioneuroblastoma are separate diseases and a rare combination in which the diagnosis can only be confirmed by pathological examination after tumor excision. We reported here a case of ganglioneuroblastoma encapsulated in pheochromocytoma. The patient is a woman, 73 years old, hypertensive, with hypothyroidism, associated for 15 years with hypercholesterolemia and hypertriglyceridemia, which had frequent complaints of low back pain. She underwent magnetic resonance and the findings were consistent with the diagnosis of pheochromocytoma. After surgery, anatomic, pathologic and immunohistochemistry analysis confirmed the diagnosis of pheochromocytoma composed by small ganglioneuroblastoma representation with the identification of small focus of infiltration of the adrenal capsule and adipose tissue by pheochromocytoma. This rare association can instigate the discussion of methods of diagnosis, more effective and more appropriate treatments for each patient.

Keywords: Pheochromocytoma; Ganglioneuroblastoma; Abdominal Neoplasms

\section{Introduction}

Prior to 2000, only six cases of a compound tumor containing Pheochromocytoma and Ganglioneuroblastoma were reported (1-3). In this context, we herein present a rare case of a patient with ganglioneuroblastoma encapsulated in pheochromocytoma.

\section{Case Report}

Woman, white, 76 years old, $68.2 \mathrm{~kg}$, married, born in Codisburgo (MG, Brazil) and living in Contagem (MG), diagnosed with hypertension when she was 66 years old. History of hypothyroidism for 15 years associated with hypercholesterolemia and hypertriglyceridemia. After treatment with common analgesics for several years, the patient persisted with complaints of constant high intensity back pain. Due to noncompliance to conventional medical treatment it was suggested to undertake magnetic resonance image (MRI) of the lumbosacral spine to perform better orthopedic workup. An ovoid structure was detected in the left adrenal gland. Consequently, an additional MRI confirmed the presence of a rounded mass lesion, heterogeneous, clear limits, located on the left adrenal gland, measuring $2.0 \times 2.0 \mathrm{~cm}$. There was important and heterogeneous contrast uptake in the tumor, these results very compatible with a diagnosis of pheochromocytoma. The patient complained of sporadic headaches and dyspnea on exertion, however, she denied dizziness, blurred vision, cold sweats or palpitations. She had been submitted to cardiovascular workup, scintigraphy and coronary angiography for further clarification of atypical chest pain. Nevertheless, coronary atheromatosis was not diagnosed.

Tab. 1: Urinary fractions epinephrine, norepinephrine, dopamine, normetanephrine, metanephrine. free cortisol and vanillylmandelic acid.

\begin{tabular}{|l|c|c|}
\hline Variable & \multicolumn{1}{|c|}{ Value } & Reference \\
\hline Epinephrine & $33.41 \mathrm{mcg} / 24 \mathrm{~h}$ & $<20$ \\
\hline Norepinephrine & $54.72 \mathrm{mcg} / 24 \mathrm{~h}$ & $<75$ \\
\hline Dopamine & $216.29 \mathrm{mcg} / 24 \mathrm{~h}$ & $<400$ \\
\hline Normetanephrine & $381.60 \mathrm{mcg} / 24 \mathrm{~h}$ & $90-440$ \\
\hline Metanephrine & $82.22 \mathrm{mcg} / 24 \mathrm{~h}$ & $50-340$ \\
\hline Cortisol & $41.80 \mathrm{mcg} / 24 \mathrm{~h}$ & $10-90$ \\
\hline Vanillylmandelic acid & $2.20 \mathrm{mg} / 24 \mathrm{~h}$ & $<6.8$ \\
\hline
\end{tabular}


On physical examination the patient was in good general condition, anxious and was typically colored. For the evaluation of the heart, the heart rhythm was regular with normal sounds, heart rate of $64 \mathrm{bpm}$, blood pressure 130/80 $\mathrm{mmHg}$ in the supine position and $120 / 85 \mathrm{mmHg}$ in standing position. The arterial pulses were rhythmic, symmetrical with excellent amplitude; absence of signals compatible with venous insufficiency.

In laboratory tests, the electrocardiogram recordedregular sinus rhythm with $\mathrm{P}$ waves, $\mathrm{QRS}$ complexes and normal repolarization. In the echocardiography examination, the size of the left atrium, the ventricular function assessed by ejection fraction and ventricular myocardial thickness

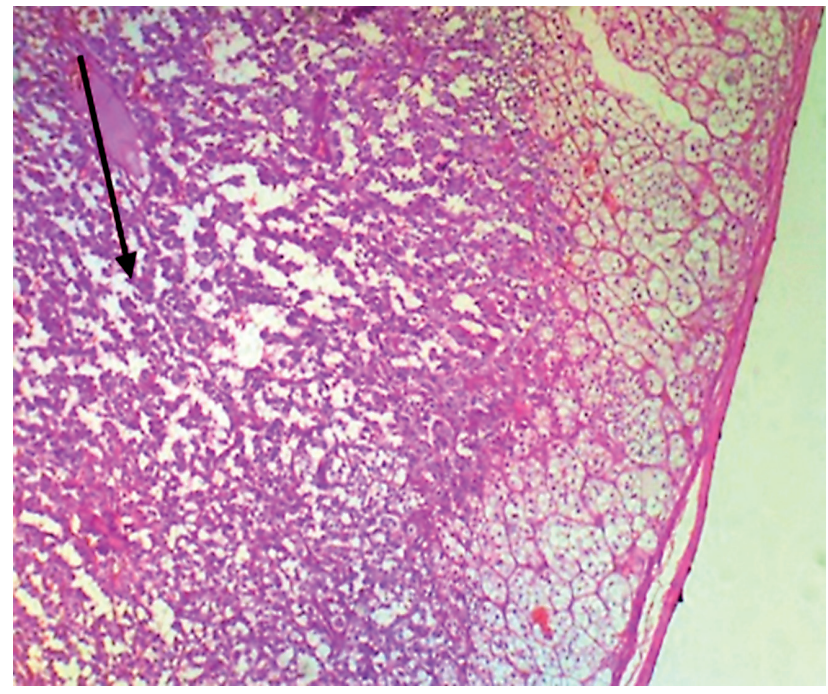

Fig. 1: Pre-surgery 131 meta-iodo-benzylguanidine scintigraphy. Optical microscopy showing neoplastic infiltration in the cortex of the adrenal gland.

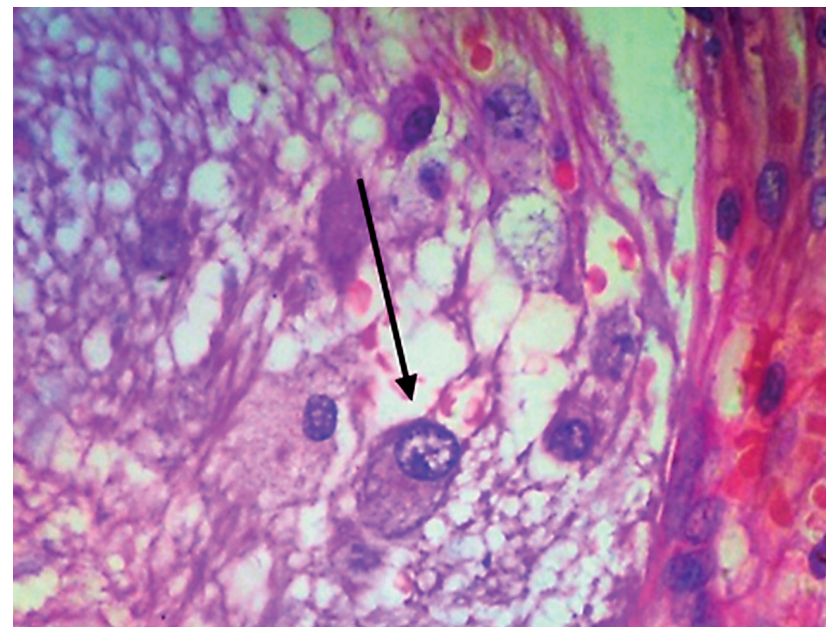

Fig. 2: Optical microscopy showing neural differentiation compatible with neoplasm of the nerve fibers and neurons.

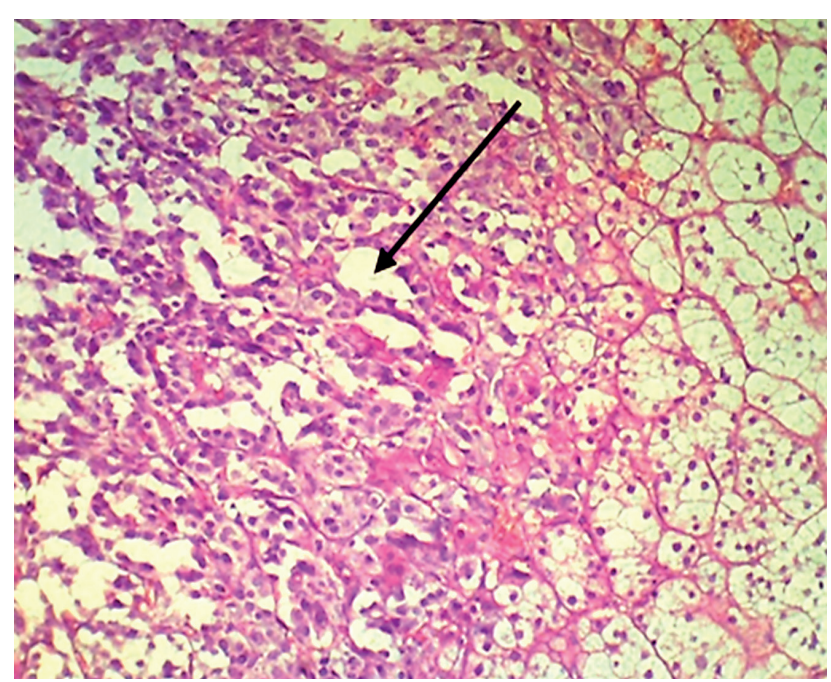

Fig. 3: Optical microscopy, at higher magnifications, showing neural differentiation consistent with neoplasia neurons and nerve fibers.

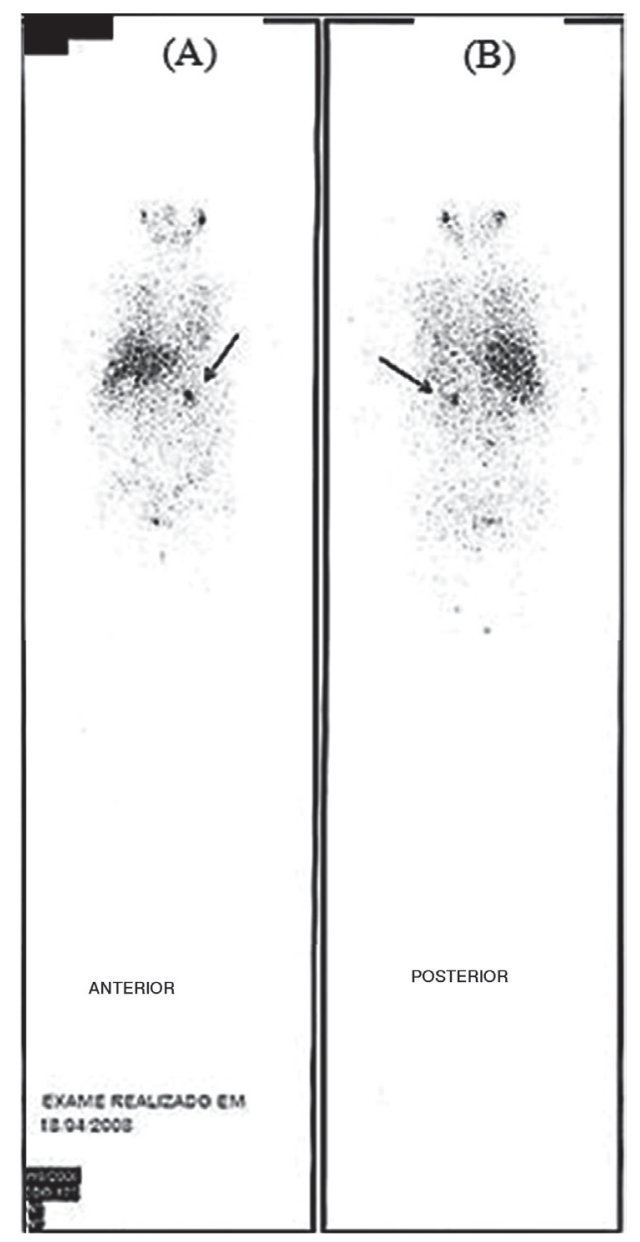

Fig. 4: Pre-surgical meta-iodo-benzylguanidine scintigraphy after tumor resection. 
(septum and free wall) and ventricular systolic and diastolic volumes were normal.

Catecholamine levels and urinary fractions were performed as epinephrine, norepinephrine, dopamine and urinary fractions, as normetanephrine, metanephrine; free cortisol and vanillylmandelic acid (Table 1).

After implementation the magnetic resonance imaging of the abdomen, abdominal scintigraphy was performed with 131 meta-iodo-benzylguanidine (MIBG) scintigraphy, which revealed the lesions illustrated in Figure 1, consistent with the presence in the left adrenal gland of pheochromocytoma projection. The diagnosis was confirmed and surgery scheduled.

A tumor infiltration adjacent to the recumbent fat tissue induced subcapsular hemorrhage, in an attempt to resect this tissue it bled and a surgical procedure was necessary.

The preoperative preparation of patients began with prazosin, prescribed in the prior week in order to conduct adrenergic blockade. There was suspension of an antihypertensive drug (atenolol) that was already administered to the patient, but due to recurrence of migraine it had been replaced by the beta blocker metoprolol $25 \mathrm{mg}$ /day. During surgery xyphopubic incision was performed for extended access to the abdominal cavity and planned subtotal adrenalectomy. The adrenalectomy was decided by the surgical team in order to assess more clearly the tumor extension. During surgery the patient presented a hypertensive peak corrected with use of sodium nitroprusside. Furthermore, there was splenic hemorrhage due to infiltration of surrounding tissue by the tumor, and it was necessary to continue to complete a splenectomy. After surgery, she progressed with hypovolemia and anemia, inducing hypovolemic shock, with the need for fluid infusion and transfusion of red blood cells. The histopathological analyzes and immunohistochemistry (Figure 2 and 3 ) confirmed the diagnosis of pheochromocytoma composed by a small intermediate ganglioneuroblastoma representation with the identification of small focus of infiltration of the adrenal capsule and adipose tissue by pheochromocytoma.

One year following surgery, another MIBG scintigraphy was undertaken, which resulted in no abnormal fixation of the radiopharmaceutical in the whole body extension, excluding tumor recurrence (Figure 4). Currently, five years after surgical treatment she is asymptomatic and without the need for antihypertensive medication.

\section{Considerations}

In this case study a difficulty was reported and it was necessary to administer use of sodium nitroprusside, the drug precursor of nitric oxide that causes vasodilation and systemic venous blood (4). This infusion rapidly reduced blood pressure, reversing the blood pressure elevations, which increase the morbidity and mortality of surgical procedure. Alternatively, the sharp fall in risk of plasma catecholamine levels after tumor resection exposed the patient to a hemodynamic instability, which progressed to hypovolemic shock and death. That is why constant monitoring of blood pressure during surgery is critical in this class of patients.

Composite pheochromocytoma-ganglioneuroblastoma is an extremely rare tumor $(1,6-12)$, given this unusual association that sparked interest in reporting the case; we confirm its importance to be source of studies and possible new treatments.

\section{References}

1. Okumi M1, Ueda T, Ichimaru N, Fujimoto N, Itoh K. A case of composite pheochromocytoma-ganglioneuroblastoma in the adrenal gland with primary hyperparathyroidism. HinyokikaKiyo 2003; 49: 269-72.

2. Santos J, Paiva I, Carvalheiro M. Pheochromocytoma: updates in diagnosis and treatment. Rev Port Endocrinol Diabetes Metabol 2009; 1: 99-111.

3. Kimura N, Miura Y, Miura K. Adrenal and retroperitoneal mixed neuroendocrineneural tumors. Endocr Pathol 1991; 2: 139-14.

4. Valenti VE, Ferreira C, Meneghini A, et al. Evaluation of baroreflex function in young spontaneously hypertensive rats. Arq Bras Cardiol 2009; 92: 205-15.

5. Bravo EL, Tagle R. Pheochromocytoma: state-of-the-art and future prospects. Rev Endocr 2003; 24: 539-53.

6. Shida Y, Igawa T, Abe K, et al. Composite pheochromocytoma of the adrenal gland: a case series. BMC Res Notes 2015; 8: 257

7. Nigawara K, Suzuki T, Onodera T, et al. Watery diarrhea, hypokalemia, achlorhydria syndrome due to recurrent malignant pheochromocytoma. Nihon Naibunpi Gakkai Zasshi 1987; 63: 923-33.

8. Nigawara K, Suzuki T, Tazawa H, et al. A case of recurrent malignant pheochromocytoma complicated by watery diarrhea, hypokalemia, achlorhydria syndrome. J Clin Endocrinol Metab 1987; 65: 1053-6.

9. Thiel EL, Trost BA, Tower RL. A composite pheochromocytoma/ganglioneuroblastoma of the adrenal gland. Pediatr Blood Cancer 2010; 54: 1032-4.

10. Prejbisz A, Harazny J, Szymanek K, et al. 7D.07: Retinal arteriolas structure in patients with pheochromocytoma. J Hypertens 2015; 33 Suppl 1: e102.

11. Puar T, van Berkel A, Gotthardt M, et al. Genotype-Dependent Brown Adipose Tissue Activation in Patients With Pheochromocytoma and Paraganglioma. J Clin Endocrinol Meta 2016; 101(1): 224-32.

12. Loper H, Kant R, Olson J, Streeten E, Munir K. Invasive phaeochromocytoma presenting as a right atrial mass. Lancet Diabetes Endocrinol 2015; pii: S22138587(15)00466-0.

Received: $16 / 10 / 2015$

Accepted: 02/03/2016 